\title{
LA INFLUENCIA DE LOS PENSADORES Y DE LOS TRADUCTORES FRANCESES EN F. PI Y MARGALL*
}

GLICERIO SÁNCHEZ RECIO

Universidad de Alicante

Francisco Pi y Margall (1824-1901) fue un hombre de gran significación política e intelectual en la España del siglo XIX. ${ }^{1}$ Como político y teórico de partido, pretendió hallar la formulación adecuada y el método preciso para resolver los graves y complejos problemas que nuestro país tuvo planteados a lo largo de la segunda mitad del siglo, y, como intelectual, procuró asimilar y completar las últimas aportaciones de la Filosofía y de las ciencias sociales, procedentes del exterior, a la vez que elaboraba su propio sistema. De este modo realizó un importante servicio cultural a España, de manera semejante al que en la misma época hicieron los krausistas. ${ }^{2}$

* Este trabajo fue presentado como comunicación en el Coloquio sobre las relaciones franco-españolas durante la Edad Media y la época contemporánea, celebrado en la Universidad de Pau, los días 28 y 29 de marzo de 1980.

1 Existe una amplia exposición de los aspectos biográficos, intelectuales y políticos en las obras:

Hennessy, C. A. M.: La República Federal en España. Pi y Margall y el Movimiento Republicano Federal, 1868-74, Madrid, 1966.

Jutglar, A.: Pi y Margall y el Federalismo Español, Madrid, 1975.

TRUJILLO, G.: El federalismo Español, Madrid, 1967.

2 Ver a este respecto las obras:

JовIт, P.: Les Educateurs de l'Espagne Contemporaine, 2 vol., París, 1936.

LOPEZ MoRILLAS, J.: El Krausismo Español, México, 1956.

CACHO VIU, V.: La Institución Libre de Enseñanza, Madrid, 1962.

GIL Cremades, J. J.: El Reformismo Español, Barcelona, 1969.

Gómez MolledA, M. D.: Los Reformadores de la España Contemporánea, Madrid, 1966. 


\section{RELACION ENTRE LA TEORIA Y LA PRAXIS POLITICA EN PI Y MARGALL}

La estrecha relación entre estos dos elementos, el pensamiento y la acción política en Pi y Margall, se dio a lo largo de toda su vida, tanto durante su larga militancia en partidos de la oposición, en el democrático primero y en el republicano-federal después, como en su breve estancia en el poder, en el primer semestre de 1873. En una y otra situaciones, su acción política estuvo iluminada por un "sistema" de ideas, y la elaboración y exposición de éste, dirigidas a fundamentar ideológicamente su partido. Esa conexión entre teoría y praxis aparecen claramente desde 1854. En la Introducción de La Reacción y la Revolución ${ }^{3}$ el autor se hacía cargo del proceso seguido por la revolución de julio de ese año, que había llevado a los progresistas al poder, y cuando trata del papel jugado por los demócratas dice:

... La primera condición de un partido es tener bien determinados sus principios, bien formulada su doctrina; la democracia desgraciadamente no los tiene. En todos sus programas se ven lastimosamente hacinados, sin sombra siquiera de orden lógico, principios políticos, económicos y administrativos; en ninguno la idea generadora de que derivan, la razón que los enlaza, la diferencia esencial que los separa del viejo dogma de los demás partidos... ${ }^{4}$

Durante la época comprendida entre 1854 y 1859 (desde la Revolución del 1854 y la publicación de La Reacción y la Revolución hasta la salida de Pi y Margall de la Redacción del periódico La Discusión) lleva a cabo la obra de crear el "sistema", explicar su contenido y definirlo con relación a los demás partidos. ${ }^{5}$

3 Pi y Margall, F.: La Reacción y la Revolución, Madrid, 1854. En esta obra el autor expone por primera vez el sistema republicano federal.

4 Pi y Margall, F.: O. c. pp. 31-33.

5 Enlazando con lo expuesto en la obra citada, publica en La Razón. Revista Política, Filosófica y Literaria. Madrid, 1856, y en La Discusión. Diario Democrático de Madrid, artículos tan significativos como los titulados:

"¿Cuál ha sido la conducta política de la democracia? ¿Cuál debía ser?", La Razón, pp. 5-18.

“¿Cuál debe ser nuestra forma de gobierno?», La Razón, pp. 97-106. 
Vuelve sobre la idea de "sistema", en La Reacción y la Revolución, al tratar de la "federación", que abarca no sólo lo político, sino también lo social y lo económico, ${ }^{6}$ en Las Nacionalidades, en $1877,{ }^{7}$ y en el Programa del Partido Republicano Federal, elaborado en $1894 .^{8}$

\section{LA METODOLOGIA Y LOS PRINCIPIOS FUNDAMENTALES DEL PENSAMIENTO DE PI Y MARGALL}

\subsection{La Dialéctica}

Pi y Margall demuestra conocer la filosofía de Hegel y utiliza su esquema de pensamiento desde sus primeros escritos en 1847. ${ }^{9}$ Más explícitas son las referencias en La Historia de la Pintura, de 1851, en donde, al tratar de la pintura europea del siglo XVI, escribe:

No comprende aún que exista esa misteriosa triada en que todo está indisolublemente unido, en que de la unidad brota la

"El partido progresista y el partido democrático», La Discuisión, 27 de marzo de 1858.

"O'Donnell y la democracia", La Discusión, 3 de febrero de 1859.

"El nuevo proyecto de ley de imprenta y la democracia", La Discusión, 20 de febrero de 1859.

Las ideas de la democracia como "escuela" y como "sistema" ya aparecían en los primeros manifiestos del partido. Ver las obras:

BLASCo lbã̃Ez, V.: Historia de la Revolución Española, 3 vol., Madrid, 1892, vol. III, p. 142.

GARRIDO, F.: Historia del Reinado del último Borbón de España, 3 vol., BarceIona, 1868-69, vol. III, apéndice, p. 50.

6 Piy Margall, F.: La Reacción y la Revolución, p. 229.

La República de 1873, p. 7, Madrid, 1874.

7 Pi Y Margall, F.: Las Nacionalidades, pp. 115-16, Madrid, 1877.

8 El documento fue publicado en El Nuevo Régimen, Semanario Federal, núm. 570, Madrid, 14 de diciembre de 1901.

9 De ese año datan sus colaboraciones en la revista El Renacimiento, Madrid, 1847. Del artículo titulado "Arquitectura India» es el siguiente párrafo: "Todo guarda armonía en la historia del género humano. Estudiado el hombre se conocen sus obras; estudiado el lugar en que aquel se desarrolla, se conoce al hombre. La unidad campea en todas partes. El universo es una composición complicadísima, dese sin embargo con la clave, y conocerás al mundo". El Renacimiento, 27 de mayo de 1847, p. 99. 
multiplicidad, de la multiplicidad la unidad, y multiplicidad y unidad son coexistentes... ${ }^{10}$

En la misma obra define la filosofía como ciencia, como teoría de la ciencia y como metodología científica, muy de acuerdo con los planteamientos hegelianos. Así escribe:

El objeto de la filosofía consiste ahora principalmente en revelar los términos contradictorios de cada antinomia y en indagar cuál puede ser el tercero que ha de abrazarlos, formando un todo sintético en que estén aquellos completamente armonizados. ${ }^{11}$

Dando un paso más, Pi y Margall se define como hegeliano "crítico" en 1854. En La Reacción y la Revolución escribe:

He leído con avidez el sistema del último genio de Occidente; no he visto levantarse ante mis ojos sino un mundo de fantasías... ${ }^{12}$

A pesar de lo anterior dice más adelante:

... El hegelianismo, dicen unos, toca ya a su término, otros que está ya sepultado entre sus propias ruinas; cuanto más, sin embargo, le examino, tanto más me convenzo de que su dirección es acertada, de que sobran en él los elementos para organizar un sistema tan conforme al más elevado racionalismo como al simple buen sentido... ${ }^{13}$

Vemos, pues, cómo a lo largo del período 1847-1854 el pensamiento de $\mathrm{Pi}$ y Margall ha pasado de la aceptación y utilización de las ideas de Hegel a la asumpción crítica del mismo. Más adelante veremos qué elementos intervinieron en esa "matización».

\subsection{Los Principios Filosóficos de Pi y Margall}

En este apartado nos acercamos al sistema filosófico de $\mathrm{Pi}$ y Margall y a la contradicción que éste encierra, por haberlo ela-

10 Pi y Margall, F.: La Historia de la Pintura, p. 279, Madrid, 1851.

11 Pi Y Margall, F.: Estudios sobre la Edad Media, p. 14, nota, Madrid, 1873. Esta obra constituye el capítulo III de La Historia de la Pintura, que se editó por sí solo en dicho año.

12 Pi y Margall, F.: La Reacción y la Revolución, pp. 244-245.

13 PI Y MARGall, F.: O. C., pp. 246-47. 
borado con elementos de origen muy diverso. El problema ya aparece en su "noción de filosofía" y en su "teoría del conocimienton, en donde se entrelazan las ideas de Hegel con las de Kant y con las de Proudhon. ${ }^{14}$

\subsubsection{La Autonomia del Hombre y la de los Grupos Sociales}

La autonomía tiene en el pensamiento de Pi y Margall la categoría de "axioma», más aún, él la califica de "dogma», como intentando reforzar su argumentación. Escribe:

Conviene formular este dogma, y voy a formularlo. Homo sibi Deus, ha dicho un filósofo alemán: el hombre es para sí su realidad, su derecho, su mundo, su fin, su Dios, su todo. Es la idea eterna, que se encarna y adquiere la conciencia de sí misma...

Un ser que lo reune todo en sí es indudablemente soberano. El hombre, pues, todos los hombres son ingobernables. Todo poder es un absurdo. Todo hombre... que trate de imponerse es un tirano. Es más: es un sacrílego.

Entre dos soberanos no caben más que pactos. Autoridad y soberanía son contradictorios... ${ }^{15}$

En este enunciado aparecen resonancias de filósofos que sostienen sistemas muy diversos, como trataremos más adelante.

En 1854 también, Pi y Margall enuncia el principio de la autonomía de los grupos sociales, como paso previo a la exposición y defensa del sistema republicano federal. Escribe:

Atiéndase de una vez a las prescripciones del simple buen sentido. Pues son verdaderas entidades naturales del Estado, la provincia, el pueblo... ${ }^{16}$

14 Pi y Margall, F.: Estudios sobre la Edad Media, pp. 50-51.

La Reacción y la Revolución, pp. 247-48.

Todas las cuestiones aqui planteadas están ampliamente tratadas en la tesis doctoral inédita del autor de este trabajo: Sánchez RECIO, G.: El Pensamiento Filosófico e Histórico de F. Pi y Margall. Facultad de Filosofía y Letras de la Universidad Complutense de Madrid, 1973.

15 PI y Margall, F.: La Reacción y la Revolución, pp. 202-203.

16

Ib., p. 276. 
Sobre este enunciado volverá el autor en 1864 para insistir tanto en él como en su amplio contenido:

El principio de la autonomía ha sido desgraciadamente mal comprendido. Es autónomo no sólo el individuo sino también la especie: lo es toda agrupación humana que haya llegado a constituir un verdadero organismo. Lo es aquí el pueblo, lo son las antiguas provincias, lo es la nación española. No son esas colectividades agregaciones fortuitas, sino necesarias; no viven vida prestada, sino vida propia; no son iguales en su modo de ser a los miembros que las componen, sino hasta cierto punto antagonistas y contradictorias; no son, en una palabra, seres morales, sino seres reales... 17

\subsubsection{La Federación}

Este principio completa lógicamente los anteriores enunciados de la autonomía. Más arriba dejamos recogida la proposición "Entre dos soberanos no caben más que pactos". De este modo, partiendo de la filosofía y del derecho político, las vertientes teórica y práctica del "sistema pimargalliano" aparecen más íntimamente relacionadas. Escribe nuestro autor:

La unidad en la variedad ha de remediar los males de una y otra: organicemos el reino sobre la base de una federación republicana. Hemos pasado ya por la tesis y antítesis (monarquía absoluta y constitucional); creemos ya la síntesis. La reclaman imperiosamente el mismo estado actual de las provincias que ayer fueron naciones, la topografía del país, la destrucción del poder, a que incesantemente aspiro... ${ }^{18}$

17 Piy Margall, F.: "Las Libertades Económicas", La Discusión, 13 de abril de 1864. Pi y Margall reafirma este principio en el momento previo a exponer la actualización de su pensamiento social, que suponia la participación del Estado en el movimiento económico.

18 PI Y MARGALL, F.: La Reacción y la Revolución, pp. 224 y ss. El autor volverá sobre este principio insistentemente. Aquí queremos recoger otras dos declaraciones muy significativas, de 1874 una, y de 1877 la otra:

"He sido partidario de la federación desde 1854. La defendí entonces calurosamente... Como la defiendo ahora, bajo dos puntos de vista, el de la razón y el de la historla», (La República de 1873, p. 7).

"La federación es un sistema por el cual los diversos grupos humanos, sin perder su autonomía en lo que le es peculiar y propio, se asocian y se subordinan al conjunto de los de su especie para todos los fines que les son comunes...", (Las Nacionalidades, pp. 115-116). 


\subsubsection{El Panteismo}

El solo enunciado de este principio junto a los anteriores produce un efecto extraño, de rechazo, es, en definitiva, contradictorio. El mantenimiento del mismo constituye el problema fundamental del pensamiento de Pi y Margall. El mismo se daba cuenta de esta dificultad; de ahí que gran parte de su actividad intelectual estuviera dirigida a intentar superar esta contradicción, viendo en esto la principal aportación que él podía prestar al progreso de la ciencia. Escribe Pi y Margall:

Hay en la historia de la ciencia un sistema casi tan antiguo como el mundo, que cual otro fénix renace incesantemente de entre sus cenizas...

Este sistema es el panteismo; es mi sistema. ${ }^{19}$

Pi y Margall justifica y defiende "su panteismo", a la vez que critica el hegeliano. ${ }^{20}$ Como conclusión de todo ello escribe:

Sí, se me dirá, pero ¿y las mil dificultades que surgen del sistema? ¿Qué realidad dais a la naturaleza? ¿Qué realidad al hombre? ¿Qué realidad a Dios? ¿Cómo explicais la libertad y la individualidad humanas? ¿En qué se diferencian según vos lo finito y lo infinito? ¿En qué se tocan y se confunden? Habéis combatido a Hegel y caído en Hegel. ¿Cómo explicais esa contradicción, cuando menos aparente? ${ }^{21}$

Aunque no responde a cada una de las anteriores interrogaciones, trata, en cambio, de armonizar la libertad con el panteismo, partiendo del principio de la doble existencia de lo particular y lo general, de lo finito y de lo infinito.

Lo general y lo particular son relativos. A mi modo de ver, como lo particular no puede destruir la realidad de lo general, lo general no puede destruir la realidad del individuo. Hegel cree lo contrario. Así, de Hegel acepto el principio, no las consecuencias, que no creo legítimas. ${ }^{22}$

Pi y Margall, F.: La Reacción y la Revolución, pp. 241-242.

20

21

Ib., pp. 245-246.

lb., pp. 251-252.

lb., p. 250 , nota. 
A pesar del anterior enunciado y de los esfuerzos de Pi y Margall, no aparece clara la armonía entre la libertad individual y la necesidad general (el panteismo), en cuanto que la primera hallará solamente su perfección, cuando coincida plenamente con la segunda.

La libertad la he definido ya cien veces, es la independencia de la voluntad de todo motivo externo, la determinación de nuestros actos por la inteligencia. Cierto que esa inteligencia, suponiento que todo el mundo sea efecto del desenvolvimiento de una sustancia o de una idea, no puede menos de obedecer a leyes necesarias; pero ¿qué se infiere acaso de esto que no sea mi libertad posible? Según mi definición, me llamo libre porque entre las inspiraciones de la razón y las del instinto, entre los motivos internos y externos, entre las leyes de la especie y la de otros seres, puedo optar por los primeros... ${ }^{23}$

Pi y Margall se mantendrá fiel a este principio filosófico durante toda su vida, encajando en el anterior esquema los nuevos elementos con los que entrará en contacto, las ideas de Darwin $y$ de Spencer. ${ }^{24}$

\section{LA INFLUENCIA DE LOS PENSADORES Y DE LOS TRADUCTORES FRANCESES EN PI Y MARGALL}

Más arriba hemos visto que Pi y Margall se declara "federal" y al mismo tiempo "panteistan y que la mayor de sus preocupaciones filosóficas fue solucionar este grave problema intelectual, que, por otra parte, resultó insoluble. Para esa difícil tarea buscó y utilizó elementos e ideas de distintos filósofos y escuelas, que ensambló entre ellos para construir un sistema, que resultó contradictorio por no haber sometido a crítica el significado auténtico de las ideas apropiadas.

23 Ib., p. 252. Sobre esta misma idea vuelve a tratar de la "ley del progreso", (Ib., p. 90).

24 PI y Margall, F.: Las Luchas de Nuestros Días. Primeros y Segundos Diálogos, pp. 436-437, Madrid, 1890.

Reflexiones Político-Sociales, p. 45, Madrid, 1901. 
Todos los autores, que se han aproximado o estudiado en profundidad el pensamiento de Pi y Margall, han insistido en una amplia red de influencias, pero haciendo, por lo general, a uno u otro autor vehículo principal de dichas influencias. Así ocurrió ya con Menéndez Pelayo, quien hablaba de la presencia de las ideas de Proudhon, de Feuerbach y de D. F. Strauss. ${ }^{25}$ Entre los autores más próximos y contemporáneos nuestros, Elías de Tejada piensa que fue Feuerbach el principal transmisor del resto de las ideas prestadas y, concretamente, de las de Hegel, y que las fuentes usadas por Pi y Margall fueron "casi siempre" de segunda mano y mal interpretadas. ${ }^{26}$ En cambio, G. Trujillo ${ }^{27}$ y Trias Bejarano ${ }^{28}$ se inclinan por Proudhon como principal elemento transmisor de las ideas adoptadas por Pi y Margall. Finalmente, A. Jutglar habla a la par de la doble influencia de Proudhon y de Hegel. ${ }^{29}$

Nosotros seguiremos la pista de esas influencias en contacto directo con los textos de Pi y Margall y de los autores presentes en su obra en torno a las ideas que más arriba hemos calificado de fundamentales.

\subsection{P. J. Proudhon}

Proudhon influye en toda la obra intelectual de Pi y Margall, en su pensamiento filosófico, en el histórico y en el social. De Proudhon tomará muchos de sus elementos; sin embargo, matizará algunas de las ideas de éste, y será, incluso condicionado por la interpretación que Proudhon hace de otros filósofos.

Tenemos noticia de los contactos habidos entre ambos pensadores, en 1852, a través de la correspondencia mantenida

Menéndez Pelayo, M.: Historia de los Heterodoxos Españoles, 3 vol., Madrid, 1881, vol. II, pp. 704-707.

TEJADA, E. DE: El hegelianismo jurídico español. Separata de la Revista de Derecho Privado, p. 63, Madrid, 1944.

27 Trujillo, G.: El Federalismo Español, p. 109.

28 Trias Bejarano, J.: Pi y Margall, Pensamiento Social, p. 33, Madrid, 1968.

29 JutglaR, A.: Pi y Margall y el Federalismo Español, vol. I, pp. 201 y ss. 
por Pi y Margall con Benet de Llanzá, Duque de Solferino, y publicada por Casimir Martí, ${ }^{30}$ a través de la cual el primero se mostraba entusiasmado por la lectura de Proudhon y confesaba estar adquiriendo la fe política y social, una vez perdida la religiosa. ${ }^{31}$

El pensamiento de Proudhon, sin embargo, ya está presente en La Historia de la Pintura, 1851, y en 1854, en el Discurso Preliminar de la edición de las Obras del P. Juan de Mariana, preparada por $\mathrm{Pi}$ y Margall; ${ }^{32}$ pero donde esa influencia aparece de forma más sistemática es en La Reacción y la Revolución, de 1854. Aquí se manifiesta en las nociónes de autonomía, en el significado y uso de la dialéctica, en la exposición de la ley del progreso, etc.

\subsubsection{La Autonomía}

Proudhon se hace cargo de esta cuestión de manera amplia en el Prólogo de su obra El Sistema de las Contradicciones Económicas Filosofía de la Miseria, publicada en $1846,{ }^{33}$ en donde parte de las conclusiones de Feuerbach en La Esencia del Cristianismo, que se había publicado en 1842. De ahí que pensemos que sea a través de Proudhon como Pi y Margall entra en el primer conocimiento de Feuerbach, que, después, como veremos, estudiará directamente. Escribe Proudhon en el Prólogo citado:

Ese Dios que tú adoras, ¡Oh hombre!, ese Dios que tú has hecho bueno, justo, todopoderoso, sabio, inmortal y santo, eres tú

30 Arvon, H.: L'Anarquisme, pp. 54-55, Barcelona, 1964.

MARTí, C.: "L'orientació de Pi i Margall cap al socialisme i la democracia. La correspondència entre $\mathrm{Pi}$ i Margall i el duc de Solferino". Recerques, núm 3 , pp. 155-197. Cartas 62 y 63, pp. 184-189, Barcelona, 1974.

31 A este respecto resulta interesante el artículo:

ROVIRA Y VIRGILI, A.: "Pi y Margall joven. Los orígenes de su Heterodoxia», El Sol, 19 de diciembre de 1930.

32 MARIANA, P. JUAN DE: Obras, 2 vol., colección dispuesta y revisada con un discurso preliminar de D. F. Pi y Margall, Madrid, 1854.

33 Nosotros hemos utilizado las traducciones de esa obra, realizadas por Pi y Margall en 1870, y por A. Bou en 1932. 
mismo; ese ideal de perfecciones es tu imagen depurada en el espejo ustorio de tu conciencia. Dios, la naturaleza y el hombre son el triple aspecto de un ser uno e idéntico; el hombre es el mismo Dios, que llega por mil evoluciones a adquirir la conciencia de sí mismo... No hay otro Dios que el que desde un principio ha dicho: Yo, no hay otro Dios que Tú.

Tales son las últimas conclusiones de la filosofía, que aspira rasgando el velo que cubría el misterio de la religión y el suyo propio. ${ }^{34}$

De este "humanismo ateo", así calificado por Proudhon, dice más adelante: "Es pues, el último término de la emancipación moral e intelectual del hombre, y por consiguiente la última frase de la filosofían. ${ }^{35}$

Pensamos que no es necesario insistir en la semejanza de este enunciado con el recogido más arriba de $\mathrm{Pi}$ y Margall. Sin embargo, juzgamos conveniente hacer referencia al contexto en el que Proudhon expone su anterior idea, tratando de defender la realidad del individuo frente a la pretendida existencia de una razón colectiva, que sería el Hombre-Dios de Feuerbach, para adoptar el método seguido por Comte para exponer su sistema social, y que suponía un cierto predominio del ser social sobre el individuo. ${ }^{36}$

Lo anterior nos conduce a tratar de la autonomía de los seres colectivos.'Proudhon rechaza la existencia de la razón colectiva, apoyándose en razones filosóficas y sociopolíticas, ${ }^{37}$ pero acepta la realidad de los seres colectivos. Escribe en $\mathrm{La} \mathrm{Fi-}$ losofía del Progreso, publicada en 1853:

34 Proudhon, P. J.: Sistema de las contradicciones económicas o Filosofía de la miseria. Traducción y prólogo de F. Pi y Margall, p. 11, Madrid, 1870.

35 Ib., 25.

36 Сомте, A.: Philosophie Positive, 6 vol., París, 1830-42, vol. II, pp. 692, 746747.

37 Proudhon, P. J: O. c., pp. 479 y ss. Termina Proudhon su argumentación de este modo: "Bastará esta última consideración para hacernos rechazar también el humanismo como sistema que tiende inevitablemente, por deificación de la humanidad, a una restauración religiosa. El verdadero remedio contra el fanatismo, según nosotros, no está en identificar la humanidad con Dios, lo cual equivale a afirmar en economia social el comunismo, y en filosofía el misticismo y el statu quo. Sino en probar a la humanidad que Dios, en el caso que lo haya, es su enemigon (O. c., p. 490). 
Yo, fundándome en la noción de movimiento, de progreso, de serie, de grupo, que de hoy más no podrá ya la ontologia dejar de tener en cuenta, y fundándome en algunos datos que suministran sobre la cuestión la economía y la historia, considero la sociedad, el grupo humano, como un ser real, constituido por la relación fluida y la solidaridad económica de todos los individuos, ya de la nación, ya de la localidad o corporación, ya de la especie entera...; considero como un ser que tiene funciones propias extrañas a nuestra individualidad..., considérolo, por fin como un ser que, habiendo salido de la naturaleza, parece ser el Dios de la naturaleza misma, de cuyas formas y leyes es en un grado superior y sobrenatural expresión y símbolo. ${ }^{38}$

Tampoco creemos necesario insistir entre la semejanza de este texto y el anteriormente recogido en Pi y Margall.

\subsubsection{La Dialéctica}

Proudhon, a través de sus obras, citó, expuso, aplicó y criticó el pensamiento y el método de Hegel. ${ }^{39}$ En su obra De la Creation de l'ordre dans l'Humanité, publicada en 1843, expone y critica el método hegeliano.

La dialéctica hegeliana, a juicio de Proudhon, tiene su origen en Kant, quíen dedujo las categorías de modo dialéctico; así, por ejemplo, las categorías, según la cantidad son: unidad (tesis), pluralidad (antítesis), y totalidad (síntesis). ${ }^{40} \mathrm{~A}$ continuación escribe:

Hegel généralisa cette idée ingénieuse. Le monde, l'universDieu, selon lui, se développe en trois moments consécutifs, for-

Proudhon, P. J.: Filosofía del Progreso. Traducción y prólogo de F. Pi y Margall, p. 49, Madrid, 1868.

En 1854, cuando Proudhon pensaba estar aplicando el método hegeliano, Pi y Margall lo calificaba de "dualista" (La Reacción y la Revolución, p. 242). En 1858, rechazará definitivamente el hegelianismo, por su falta de adecuación a la realidad (Proudhon, P. J.: Teoría de la Propiedad, traducción de C. Lizárraga, pp. 58-60, Madrid, 1873. Esta obra se había publicado en 1866). Ver también: LUBAC, H. DE: Proudhon y el cristianismo, Madrid, 1965.

40 Proudhon,'P. J.: De la creation de l'ordre dans l'humanité. 2. a edict., p. 133, París, 1849. 
mant entre eux les termes et le période de l'eternelle évolution, Moi, Non-Moi, Absolu. ${ }^{41}$

Tratando de caracterizar la sintesis escribe:

La synthèse ne détruit pas réellement, mais formellement, la thèse et l'antithèse...

La synthèse n'est pas un juste-milieu... En religion et en philosophie, le juste-milieu est une trahison: dans la science, une absurdité.

La synthèse n'est pas non plus un éclectisme: elle ne consiste pas à souder la moitié d'une idée à la moitié d'une autre idée: elle est la resolution compléte et la combinaison intime de la thèse et de la antithèse. ${ }^{42}$

\subsubsection{La Federación}

La relación existente entre ambos autores respecto a este concepto ha sido tratada ampliamente por G. Trujillo y por A. Jutglar, ${ }^{43}$ insistiendo ambos en la prioridad de $\mathrm{Pi}$ y Margall en el uso de la federación como principio de Derecho Político. ${ }^{44}$ Proudhon, en cambio, había tratado de la federación como medio para la reforma económica desde 1841, en La Segunda Memoria sobre la Propiedad. ${ }^{45}$ Más aún, en 1851, publicó otra obra titulada Idea General de la Revolución en el Siglo XIX, en la que trataba de la disgregación del poder político dentro de la organi-

41 Ib., p. 133.

42 Ib., pp. 189-190.

43 JUTGLAR, A.: O. c., pp. 206-207.

TRUJILLO, G.: O. c., pp. 118-119.

44 En España se habían publicado anteriormente obras respecto a esta cuestión. TRUJILLO, G.: O. c., pp. 136-137.

GARRIDO, F.: La República Democrática Federal Universal. 16. ${ }^{a}$ edic., Madrid, 1881. Esta obra se publicó en 1855. En la dedicatoria habla el autor de sus actividades propagandísticas a favor de la República Democrática Federal desde 1842.

La Federación y el Socialismo. Presentación de Jorge Maluquer de Motes, Barcelona, 1970.

MALUQUER DE MOTES, J.: El Socialismo en España, 1833-1868, Barcelona, 1977.

Proudhon, P. J.: Qu'est ce que la propiété. Deuxième mèmoire. 2. ${ }^{a}$ edict., París. 1848. Este ha sido el ejemplar consultado por nosotros. 
zación económica, idea que pudo ser recogida por Pi y Margall en La Reacción y la Revolución ${ }^{46}$ en donde escribia:

Mas examino atentamente las condiciones de esta nueva sociedad y observo que para fundarla, no sólo es necesario acabar con la actual organización política, sino también con la económica; que es indispensable, no ya reformar la nación, sino cambiar la base; que a esto se oponen infinitos intereses creados, una preocupación de siglos que nadie aún combate, una ignorancia casi completa de la forma y fondo de ese mismo contrato individual y social que ha de sustituir la fuerza... ${ }^{47}$

\subsubsection{Otras ideas Proudhonianas en el Pensamiento de Pi.y Margall}

Hemos tratado con más detención de la presencia de Proudhon en los principios fundamentales de Pi y Margall; sin embargo, ella se acusa casi a lo largo de toda su obra, principalmente en el pensamiento histórico y social.

Ambos autores no están de acuerdo en cuanto a la categoría científica de la Historia, ciencia para Pi y Margall, ${ }^{48}$ nociencia para Proudhon. ${ }^{49}$ En cambio, hay más acuerdo en torno a la ley de progreso. ${ }^{50}$ En el Prólogo de Pi y Margall a La Filosofía del Progreso de Proudhon, escribía:

Este libro empezará por enseñarles que el progreso es ley, no sólo de la humanidad, sino también del universo; que no vive sino

Proudhon, P. J.: Idea General de la Revolución en el siglo XIX, Madrid, 1868. El estudio VII lleva por título "Disolución del gobierno en el organismo económicon, pp. 168-223.

PI Y MARgall, F.: La Reacción y la Revolución, pp. 204-205.

PI Y MARGall, F.: Estudios de la Edad Media, pp. 6-7.

PRoudhon, P. J.: De la creation de l'ordre dans l'humanité, p. 341. Escribe el autor: "Puis done que l'objet de l'histoire est multiple, il s'ensuit que l'histoire n'est point science, mais, selon l'etimologie du mot, exposition, tèmoignage: par consequent son utilité consiste, d'un part à confirmer, ou s'il y a bien, à démentir par les faits les hypotèses de la theorie; d'autre part à nous révéler le travail de la nature dans la creation de l'ordre".

PI Y Margall, F.: La Reacción y la Revolución, pp. 84-85.

Proudhon, P. J.: De la Creation de l'Ordre dans I'Humanité, p. 344. 
lo que está en perfecta mudanza; que el quietismo es la muerte... ${ }^{51}$

La relación entre ambos autores es más continua en el pensamiento social: para ambos la revolución democrática tiene el doble carácter de "política y social». ${ }^{52}$ En sus escritos, Pi y Margall hace referencia repetidamente a las ideas de Proudhon sobre el socialismo y la propiedad. En el artículo El Socialismo ${ }^{53}$ escribía:

¡Socialistas! ¿y quién duda que lo somos, si por socialismo se entiende toda tendencia a mejorar la condición de las clases pobres? Nosotros hemos rechazado ese socialismo que tiende a absober el individuo en el Estado; jamás hemos condenado las reformas posibles dentro de la libertad del individuo. ¿Se nos cita a Proudhon? ¡Cuán mal le ha de conocer el que le cita! De ninguna otra pluma que de la de Proudhon ha recibido el Estado por el socialismo más tremendós ni más certeros golpes.

La misma relación existe respecto a la asociación y a la federación de asociaciones como medio de establecer la nueva estructura política y socio-económica. ${ }^{54} \mathrm{Y}$, finalmente, la exposición y el intento de aplicar la idea proudhonianá del Banco de Cambio Directo. ${ }^{55}$ Hay una última idea de Proudhon, que $\mathrm{Pi}$ y Margall recogerá en 1864, cuando se ha producido un cambio en su pensamiento social, es la de la justicia, con categoría de idea innata. ${ }^{56}$ Escribe Pi y Margali, tratando del socialismo:

51 Proudhon, P. J.: Filosofía del Progreso. Traducción y prólogo de Pi y Margall, pp. 1-2, Madrid, 1868.

52 Proudhon, P. J.: O. c., pp. 16-17.

PI y Margall, F.: La Reacción y la Revolución, pp. 204-205.

"El Partido Absolutista", La Discusión, 7 de abril de 1858.

"Asociaciones Obreras", ib., 8 de septiembre de 1858. Ver también la nota 46.

53 Artículo publicado en La Discusión, 5 de febrero de 1858.

54 Ver la nota 46 y el artículo "Asociaciones Obreras", citado en la nota 52.

55 PI Y MARGALL, F.: “Las clases jornaleras", XI-XV, La Discusión, 24, 2628 de noviembre, 4 de diciembre de 1857 y 4 de julio de 1863.

Proudhon, P. J.: La Solución del Problema Social, Madrid, 1869.

56 Proudhon, P. J.: De la Justice dans la Revolution et dans I'Eglise, 3 vol., Bruxelles, 1862, vol. I, Etude ler., p. 58. 
Templar la guerra entre el capital y el trabajo es su fin inmediato; hacer conspirar todas las reformas legislativas a la emancipación de las clases jornaleras, su fin mediato; establecer el imperio de la justicia absoluta en las relaciones sociales, su fin supremo. ${ }^{57}$

La aplicación de esta idea ha de suponer la intervención del Estado, principio por el cual se rompía con los planteamientos de la Economía Liberal. ${ }^{58}$

\subsection{Otros Pensadores Franceses}

Queremos referirnos en este apartado brevemente a la influencia de otros dos autores en Pi y Margall:

1) L. Blanc, autor al que retoma en $1864,{ }^{59}$ al desarrollar la idea del crédito a través del Estado ${ }^{60}$ en favor de las asociaciones productoras formadas por obreros, después de haberlo criticado en 1857, cuando se oponía a la intervención del Estado en el proceso de la producción. ${ }^{61}$

2) Comte. Pi y Margall había tenido alguna relación con este último a través de los escritos de Proudhon; sin embargo, el contacto más directo y profundo se produjo a partir de 1866 durante su exilio en París, en donde, incluso, estudió la filosofía positiva con algunos de los discípulos directos de Comte. ${ }^{62}$ Esta influencia la manifestaría claramente en sus escritos durante la Restauración desde el doble aspecto metodológico y moral.

57 Pi y Margall, F.: “¿Somos socialistas?», La Discusión, 17 de mayo de 1864. El subrayado es nuestro.

58 Pi y Margall, F.: "La asociación y el crédito", La Discusión, 3 de julio de 1864.

59 Ver el artículo citado en la nota 58.

BLANC, L.: Organisation du Travail, París, 1839. Nosotros hemos utilizado la novena edición publicada en 1850, procedente de la biblioteca particular de Pi y Margall, donada a la Biblioteca Nacional, en Madrid.

60 Blanc, L.: O. c., pp. 172 y 179.

61 PI Y MARGall, F.: "Las clases jornaleras", IV-VIII, La Discusión, 7, 10, 12, 14 y 17 de noviembre de 1857.

62 Caravaca, F.: Pi y Margall, p. 67, Barcelona, 1935. 
Respecto al primero escribe en el Prólogo de Las Nacionalidades (1877):

Deseoso de estar lo más posible en la realidad, hasta he seguido el método opuesto al que generalmente se emplea. En vez de partir de hipótesis, más o menos admitidas, he observado atentamente los hechos, y por el examen de las leyes a que obedecen he llegado a las doctrinas que sostengo.

A pesar de esta afirmación y de algunas otras innovaciones, Pi y Margall mantendría el mismo cuerpo de doctrina, como lo expondría en Las Luchas de Nuestros Días (1887-1890).

También en las obras de esta época muestra especial interés por la moral: Las Luchas de Nuestros Días, Las Reflexiones Político-Sociales (1901) ${ }^{63}$ y Cartas Intimas (Obra Póstuma, 1911). Este interés ya se había manisfestado en el Prólogo a La Filosofía del Progreso de Proudhon, en 1868. En todas estas obras está presente la concepción comtiana de la moral. ${ }^{64}$

\subsection{Los Traductores Franceses}

Tratamos de los traductores franceses como transmisores de las ideas de los filósofos alemanes: Hegel, Feuerbach y D. F. Strauss.

Los biógrafos de Pi y Margall han insistido en su conocimiento de la lengua alemana. En primer lugar, advertimos que en 1844 se publicó en España una gramática alemana, en la que colaboró Sanz del Río. ${ }^{65}$ Por otra parte, contamos con el propio testimonio de $\mathrm{Pi}$ y Margall, en 1850, sobre sus estudios del alemán. ${ }^{66}$ Sin embargo, hemos comprendido que el conocimiento que tenia de Hegel en 1854 no era profundo ni, probablemen-

63 Ver la nota 24

PI y Margall, F.: Cartas Intimas, Madrid, 1911. Obra póstuma.

64 ComTE, A.: Catecismo Positivista, (1852).

Nosotros hemos utilizado la traducción de A. Zozoya, publicada en Madrid en 1887.

65 SAnz del Río, J.: Textos escogidos. Edición preparada por E. Terrón, pp. 6465, Barcelona, 1968.

66 MarTi, C.: Artículo citado, pp. 176 y 178. Cartas núm. 45 y 51. 
te, directo; en cambio, sí lo parecia el de Feuerbach y de Strauss. Por otra parte, ya aparecen referencias del conocimientos de esa lengua en $1857 \mathrm{y}$, más tarde, en $1902 .{ }^{67}$

Ante esto pensamos que la explicación debía hallarse en las traducciones que de esos autores existían entre 1840 y 1850.

\subsubsection{Los traductores de Hegel}

Más arriba nos hemos referido a la presencia del pensamiento de este filósofo en los escritos de Pi y Margall. No vamos a tratar aqui de esta cuestión porque excede los límites de nuestro trabajo. En La Reacción y la Revolución, a pesar del conocimiento, que dice tener, del sistema hegeliano, ${ }^{68}$ el autor no cita ninguna de las obras de Hegel, aunque hace claras referencias a Las Ideas Estéticas, a La Fenomenología del Espíritu, a La Filosofía del Derecho y a La Filosofía de la Historia. Lo primero que nos puso sobre la pista de los traductores y expositores de Hegel fue la concepción que tanto Proudhon como Pi y Margall tenían acerca de la "Dialéctica hegeliana", de la "mediación", expuesta por Hegel en la Fenomenología del Espíritu de la siguiente manera:

... Porque la mediación no es sino la semoviente igualdad consigo misma o la reflexión sobre sí mismo, el momento del yo que es para sí mismo, la pura negatividad, o, reducido a su pura abstracción, el simple devenir. ${ }^{69}$

Posteriormente, descubrimos la traducción al francés de Las Ideas Estéticas de Hegel, realizada por Mr. M. Ch. Bernard

67 PI y MARgall; F.: "Revista bibliográfica», La Discusión, 1 de diciembre de 1857.

"Caución", (Poema de Schiller, traducido por Pi y Margall), El Nuevo Régimen, Semanario Federal, 29 de diciembre de 1902.

Ver la nota 12.

69 Hegel: La Fenomenologia del Espíritu, pp. 26-28, Madrid, 1935. Es conveniente recordar la polémica entre Marx y Proudhon sobre este misma cuestión. MARX, C.: La miseria de la filosofía. Traduc. de D. Negro Pavón, p. 249, Madrid, 1969. 
en $1840,{ }^{70}$ que Pi y Margall pudo conocer en el seno de La Sociedad Filomática de Barcelona. ${ }^{71}$ En dicha obra se lee:

La faculté la plus élevée que puisse refermer en lui-même le sujet, nous l'appelons d'un seul mot la liberté. La liberté est la plus haute destination de l'esprit. Elle consiste en ce que le sujet ne rencontre rien d'etranger, rien que le limite dans ce qui est en face de lui, mais s'y retrouve lui-même. Il est clair qu'alors la necessité et le malheur disparaisent. Le sujet est en harmonie avec le monde et le satisfait en lui. Là expire toute opposition, toute contradiction... Telle est la région du vrai absolu dans le sein duquel la liberté et la necessité, l'esprit et la nature, la science et son objet, la loi et le penchant, en un mot tous les contraires s'absorvent et se concilient. S'élever par la pensé pure à l'inteligence de cette unité qui est la verité même tel est le but de la philosophie. ${ }^{72}$

Ante estos textos, por tanto, debemos concluir lo siguiente:

a) Que el pensamiento de Hegel está diversamente expuesto en La Fenomenología del Espiritu y en Cours d'Esthetique. La traducción de esta última la consideramos correcta, al contrastarla con otra versión reciente de la misma obra. ${ }^{73}$

b) Que las exposiciones de Proudhon y de Pi y Margall son semejantes entre si, y que la de este último incluso, se aproxima más a la de Hegel, teniendo ambas por modelo la de Cours d'Esthetique.

Como consecuencia de todo ello, pensamos que Pi y Margall conoció, primero, la versión de Cours d'Esthetique y que dicha interpretación, posteriormente, se afianzó con las lecturas de Proudhon.

70 Hegel: Cours d'Esthetique. Analisé et traduit en partie par Mr. M. Ch. Benard, 5 vol., París 1840 . Más tarde esta obra fue traducida al castellano por M. Granell: HEGEL: De lo bello y sus formas, $3 .^{a}$ edic., Madrid, 1958.

71 Caravaca, F.: O. c., p. 19.

72 HEGEL: Cours d'Esthetique, vol. I, pp. 71-74.

73 HeGEL: Introducción a la Estética. Versión de R. Mazo, p. 50, Barcelona, 1971. 
Pi y Margall se adentró, además, en el conocimiento de Hegel a través de las exposiciones de Tennemann ${ }^{74}$ y del krausista Ahrens. ${ }^{75}$ Finalmente, también pudo conocer, aunque supere los límites de este trabajo, la traducción italiana, lengua que conocía, de la Filosofía de la Historia, realizada por Paserini en $1840 .{ }^{76}$

En las obras posteriores a 1854, Pi y Margall no manifiesta haber superado estas deficiencias en la intelección de Hegel, a pesar de sus posibles lecturas directas en alemán.

\subsubsection{La Traducción de Feuerbach}

Hay dos aspectos de la obra de Pi y Margall en los que la influencia de Feuerbach es clara, el de la autonomía del individuo y el de la solución del problema de las relaciones entre lo concreto y lo general.

El contacto entre estos dos hombres, pensamos que, en primer lugar, vino dado a través de la obra de Proudhon Sistema de las Contradicciones Económicas; sin embargo, Pi y Margall recoge y utiliza ideas, algunas no tratadas y otras con finalidad distinta a la dada por Proudhon. De ahí que pensáramos en otra vía de contacto. En 1850 se publicó en Paris una obra titulada Qu'est-ce que la Religion, en la que se recogían traducidos al francés varios trabajos de Feuerbach, entre ellos La Esencia del Cristianismo, que, a su vez, se había publicado en $1842 .{ }^{77} \mathrm{~A}$ través de esa obra Pi y Margall entró en contacto directo con su autor.

Feuerbach concibe su obra como una reacción contra el idealismo filosófico, para terminar atrapado completamente por él. Escribe en La Esencia del Cristianismo:

74 Tennemann: Manuel de Histoire de la Philosophie, 2. vol. Traduction de V. Cousin, 2. a edict., París, 1839. En las p. 347-351 del vol. II, hay una excelente exposición del sistema de Hegel. Esta obra es citada por Pi y Margall en los Estudios de la Edad Media, p. 64.

75 Ahrens: Curso de Psicología. Traduc. de G. Lizárraga, 2 vol., Madrid, 1873. La primera edición francesa de esta obra es de 1835. El autor expone a Hegel en el vol. I, pp. 57-62, y en el vol. II, pp. 186-187.

76 Hegel: Filosofía de la Historia. Traduc. de J. Gaos, Madrid, 1928.

77 Ewerbeck, H.: Qu'est-ce que la Religion, París, 1850. 
En effet, vous no recontrerez dans ma philosophie ni la substance de Spinoza, ni le moi de Kant et de Fichte, ni l'identité de Schelling, ni l'esprit absolu de Hegel... Son principe est un être réel, le plus réel de tous, l'être réel per excellence, en un mot I'homme. ${ }^{78}$

Ahora bien, el hombre es definido por una trinidad de facultades, por «tres potencias supremas»: la razón, la voluntad y el amor:

Cette trinité humaine ou humanitaire existe donc, si je puis m'exprimer ainsi, pour ella-même; cette trinité, je l'appelle absolue, divine, parce que sans elle, l'homme individuel, ne serait rien. II ne faut donc point dire: il possède ces trois forces-là; ces trois forces, comprises sans un nom unitaire, c'est l'homme. ${ }^{79}$

De este modo, el hombre real coincide con lo general, con la esencia humana, y este es, en definitiva, el hombre autónomo:

La raison c'est l'être indépendant et libre, basé sur lui-même, l'être autonome par excellence. ${ }^{80}$

Por las anteriores afirmaciones, puede comprenderse lo siguiente:

L'homme, il est vrai, porte ainsi en lui-même ce qu'il adore sous le nom de Dieu, de l'être suprême, mais non en lui comme individu. Aucun de tous les individus composant un genre, n'est égal en valeur a ce genre... II ne faut pas oublier, en autre, que cette grande et belle nature de l'être humain, cette sublime et riche idée, apparait à l'individu, ordinairement sous la forme d'un individu, ainsi, l'enfant s'incline devant elle sous l'image de son père, de sa mère, l'élève s'incline devant elle sous l'image de son précepteur; homo homini Deus est. ${ }^{81}$

De este modo define y explica Feuerbach su concepto del hombre real, pero dentro del campo del idealismo, que pretendía combatir. En un paso más aporta su solución al problema de las relaciones entre lo singular y lo universal, que después adoptará Pi y Margall. Escribe Feuerbach:

78 EWERBECK, H.: O. c., p. 70.

79 lb., pp. 78-79.

80 lb., p. 138.

81 lb., pp. 111-112. 
En effet, dans les relations qui existent entre la conscience humaine et les objets naturals ou matériels, je distingue cette conscience en une cónscience qu'on a de l'objet matériel et la conscience du moi, ou la conscience de la conscience. Dans la contemplation de l'objet de la réligion, cependant, ces deux faces de la consciencè ne font plus que une. ${ }^{82}$

Y más adelante, escribe:

La raison ne trouve qu'en elle-même la source comme le but de l'univers; elle deduit donc nécessairement toute chose de son Dieu, c'est-à-dire de la raison. Elle n'adore Dieu que quand il hormonise avec elle... ${ }^{83}$

\subsubsection{La Traducción de D. F. Strauss}

Pensamos que el pensamiento de este último autor está presente al tratar Pi y Margall del cristianismo, cuando habla de las contradicciones entre la doctrina y la práctica posterior, ${ }^{84}$ y de la relación entre la doctrina de Jesucristo y la de los esenios. ${ }^{85}$ El origen de las contradicciones del cristianismo estaría en la introducción del "dualismo" entre el cielo y la tierra, idea que habia sido desarrollada por Feuerbarch. ${ }^{86}$

\section{CONCLUSION}

Una vez expuestas las ideas que los pensadores y los traductores franceses suministraron a $\mathrm{Pi}$ y Margall, queremos recoger un texto de éste para ver cómo utiliza las de unos y de otros,

82 Ib., p. 114.

83 lb., p. 138.

84 PI Y MARgall, F.: Estudios sobre la Edad Media, pp. 28-30.

Strauss, D. F.: Vie de Jesus ou Examen Critique de son Histoire. Traduction de E. Littré, 4 vol., 2. ${ }^{a}$ ediction, París, 1853. La primera edición en alemán se publicó en 1835. En el vol. II, pp. 525 y ss., dice el autor que el plan de Jesús era moralizante y religioso, y, aunque esperaba mediante él reformar politicamente el pueblo, nunca pensó el mismo dedicarse a tal renovación.

85 PI Y MARGall, F.: O. c., pp. 78-81. Strauss, D. F.: O. c., vol. I, p. 348.

86 PI y MARGall, F.: Estudios sobre la Edad Media, pp. 29-30.

La Reacción y la Revolución, p. 117.

EWERBECK, H.: O. c., pp. 158-159. 
intentando amalgamarlas en un "sistema", que puede calificarse como "eclecticismo moderno" ${ }^{87}$

... Sigue Hegel aplicando el principio ("lo general es la esencia de las cosas") a lo que llama espíritu; y así, da por substancia al del individuo el de la familia, al de la familia el del Estado, al del Estado el de la especie. Ahora bien, si lo general es la esencia y la única realidad posible de las cosas lo creo una consecuencia inevitable, lo más general es lo más real, lo más real es, relativamente al espíritu, el espíritu del linaje humano. Como la nada es, pues, la virtualidad de Dios; el espíritu universal, y no el individual, ha de ser el Dios ya realizado. Estamos, pues, en plenísimo humanismo. El hombre-realidad existe; la humanidad-individuo es aún, como el astro y la flor, un accidente. ¿Qué se ha hecho de mi libertad? ¿Qué de mi personalidad y mi soberanía? ${ }^{88}$

Para resolver el problema de las relaciones entre lo individual y lo universal nuestro autor, por lo tanto, abandona el planteamiento proudhoniano, aceptando el. de Hegel, pero salva el valor del individuo a través de las aportaciones de Feuerbach, acercándose así al planteamiento de los krausistas. ${ }^{89}$

Ferrater Mora, J.: Diccionario de Filosofía, 2 vol., Buenos Aires, 1971, 5. a edic., 2. ${ }^{2}$ reimpresión. Voz «Eclecticismo», vol. I, pp. 495-497. Madrid, 1841, vol. II, pp. 35-37.

SANZ DEL RIO, J.: O. C., pp. 90-95. 